\title{
Ultrastructural and Cytochemical Aspects of the Interaction Between the Mycoparasite Pythium oligandrum and Soilborne Plant Pathogens
}

\author{
Nicole Benhamou, Patrice Rey, Karine Picard, and Yves Tirilly
}

First author: Recherche en Sciences de la vie et de la santé, Pavillon Charles-Eugène Marchand, Université Laval, Sainte-Foy, Québec, Canada, G1K 7P4; and second, third, and fourth authors: ESMISAB, Laboratoire de Microbiologie et Sécurité Alimentaire, Université de Brest, Technopole Brest-Iroise, 29280, Plouzané, France. Accepted for publication 4 March 1999.

\begin{abstract}
Benhamou, N., Rey, P., Picard, K., and Tirilly, Y. 1999. Ultrastructural and cytochemical aspects of the interaction between the mycoparasite Pythium oligandrum and soilborne plant pathogens. Phytopathology 89:506-517.

The interaction between the oomycete Pythium oligandrum and various soilborne oomycete and fungal plant pathogens ( $P$. ultimum, $P$. aphanidermatum, Fusarium oxysporum f. sp. radicis-lycopersici, Verticillium albo-atrum, Rhizoctonia solani, and Phytophthora megasperma) was studied by light and electron microscopy in order to assess the relative contribution of mycoparasitism and antibiosis in the antagonistic process. Scanning electron microscope investigations of the interaction regions showed that structural alterations of all pathogenic fungi and oomycetes (except for Phytophthora megasperma) occurred soon after contact with the antagonist. Light and transmission electron microscope studies of the interaction region between the antagonist and P. ultimum revealed that intimate contact between both partners preceded a sequence of degradation events including aggregation of host cytoplasm and pene-

similar scheme of events was observed during the interaction between $P$. oligandrum and $F$. oxysporum f. sp. radicis-lycopersici, with the exception that complete loss of host protoplasm was associated with antagonist invasion. The interaction between P. oligandrum and $R$. solani resulted in an abnormal deposition of a wall-like material at potential penetration sites for the antagonist. However, the antagonist displayed the ability to circumvent this barrier and penetrate host hyphae by locally altering the chitin component of the host hyphal wall. Interestingly, antagonist cells also showed extensive alteration as evidenced by the frequent occurrence of empty hyphal shells. In the case of Phytophthora megasperma, hyphal interactions did not occur, but hyphae of the plant pathogen were damaged severely. At least two distinct mechanisms appear to be involved in the process of oomycete and fungal attack by P. oligandrum: (i) mycoparasitism, mediated by intimate hyphal interactions, and (ii) antibiosis, with alteration of the host hyphae prior to contact with the antagonist. However, the possibility that the antagonistic process may rely on the dual action of antibiotics and hydrolytic enzymes is discussed.
\end{abstract} tration of altered host hyphae. Localization of the host wall cellulose component showed that cellulose was altered at potential penetration sites. A
Additional keywords: biological control, gold cytochemistry.
In recent years, the cellular and molecular biology of biological control mediated by antagonistic fungi and oomycetes has been studied extensively (16). Research in plant pathology and molecular biology has focused on fungal antagonism for two quite different reasons. On the one hand, evidence has been provided that understanding the exact mechanisms underlying the antagonistic process was an essential prerequisite for future developments in terms of selection of the best biocontrol agents according to their predicted behavior (10). On the other hand, it has become apparent that the interplay between an antagonist and a plant pathogen is not a simple process mediated by one single biologically active molecule, but rather involves an extensive exchange of molecular signals that, in turn, evokes a complex response leading to a series of events expressed synchronously $(1,5,27)$. However, in spite of major advances in our understanding of how to manipulate mycoparasitic organisms, examples of practical use of such microorganisms as biological control agents are few, even though encouraging results have been reported with the oomycete Pythium oligandrum (24) and with true fungi including Trichoderma spp. (12) and Gliocladium virens (17). The major challenge now is how to select a biocontrol agent on the basis of its specific potential to control pathogen populations and to reduce plant disease incidence.

Corresponding author: N. Benhamou; E-mail address: nben@rsvs.ulaval.ca

Publication no. P-1999-0426-01R

(C) 1999 The American Phytopathological Society
Among the commonly occurring Pythium species in various soil types, $P$. oligandrum Drechs. has been reported to be an aggressive colonizer capable of attacking a wide range of plant-pathogenic oomycetes and true fungi $(19,22)$. In spite of this broad host spectrum, the mechanisms by which this oomycete provides biological control against soilborne plant pathogens appear to be selective, probably because highly specific molecular events at the cell surface, as well as differential production of biologically active molecules, determine the outcome of a given interaction ( 7 , 8,23 ). While the ability of $P$. oligandrum to compete with root pathogens for saprophytic colonization of substrate is thought to be of critical importance for preventing pathogen inoculum increases in soil (24), a number of other mechanisms including antibiosis (29) and enzyme production (22) have been proposed as potential strategies in the antagonistic process (22). However, the situation is currently not defined clearly and the possibility that both mechanisms may operate synergistically is an option that needs to be investigated at the cell and molecular levels.

Since the pioneering work of Deacon (11) on the antagonistic properties of $P$. oligandrum, little has been reported on the cytological and molecular events involved in the interaction between this mycoparasite and plant pathogens, although marked differences in terms of host susceptibility have been observed (14). Recent video-microscopical investigations revealed that host susceptibility to $P$. oligandrum correlated with growth inhibition and host hyphal coagulation, vacuolation, or both (21). Because most earlier works have mainly relied on visual or light microscope observations, very 
little information is available on two key questions: (i) to what extent does the mycoparasite actually attack plant pathogens and establish itself within the host cells, and (ii) what is the relative or sequential contribution of mycoparasitism and antibiosis in these interactions? Elucidating the cytological events involved in a given interaction is an essential complement to biochemical investigations and is of particular relevance when studying their biological significance in relation to possible pathogen suppression.

In an attempt to address these important questions, we investigated, by scanning and transmission electron microscopy, the interaction between $P$. oligandrum and various damaging plant pathogens. The objectives of the current research were first, to determine the pattern of host colonization by $P$. oligandrum; second, to delineate the biological events underlying the different interactions; and third, to investigate cytochemically the relative importance of hydrolytic enzymes in the process.

\section{MATERIALS AND METHODS}

Fungal culture and growth conditions. The strain of $P$. oligandrum (isolate 1010) used in this study was isolated from pea roots in Denmark. It was grown on potato dextrose agar, yeast malt agar, or V8 agar at $24^{\circ} \mathrm{C}$ in the dark and subcultured every week. Hyphal growth was markedly stimulated on V8 agar. This medium ( $200 \mathrm{ml}$ of $\mathrm{V} 8$ juice, $2.5 \mathrm{~g}$ of $\mathrm{CaCO}_{3}, 0.1 \mathrm{~g}$ of $\beta$-sitosterol, and $15 \mathrm{~g}$ of agar per liter) was selected for dual culture test experiments.

The antagonistic activity of $P$. oligandrum was tested against the following root pathogens: P. ultimum Trow, isolate BARR 447 (Center for the Land and Resources Research, Ottawa, Ontario Canada); P. aphanidermatum; Fusarium oxysporum Schlechtend.:Fr. f. sp. radicis-lycopersici W.R. Jarvis \& Shoemaker, isolated from naturally occurring tomato plant disease; Verticillium albo-atrum Kleb. (Robert Hall, University of Guelph); Rhizoctonia solani Kühn, (AG-4) (Ilan Chet, The Hebrew University of Jerusalem); and Phytophthora megasperma (Agriculture Canada, Ste-Foy, Quebec, Canada).

Dual culture tests. Hyphal interactions between $P$. oligandrum and the different plant pathogens were studied according to the following procedure. Agar disks (5 $\mathrm{mm}$ in diameter) were collected from the growing margin of fresh cultures of $P$. oligandrum and the various plant pathogens and placed $3 \mathrm{~cm}$ apart on the surface of a freshly prepared agar medium. Plates were allowed to grow at $25^{\circ} \mathrm{C}$ under continuous light. The antagonist and its host grew toward each other, and mycelial samples from either the interaction region or the edge of the plant pathogen colony when contact between both partners did not occur were collected by 2 and 3 days after inoculation and processed for electron microscopy.

Scanning electron microscope studies. Mycelial samples were vapor-fixed with $2 \%$ (wt/vol) aqueous osmium tetroxide for $20 \mathrm{~h}$ at room temperature, air-dried, and sputter-coated with gold palladium in a Polaron E 500 sputter coater (Polaron, Cambridge, England). They were kept in a dessicator until examination with a Cambridge Stereoscan 5-150 scanning electron microscope (LEO Electron Microscopy Ltd., Cambridge, England) operating at $20 \mathrm{kV}$. Micrographs were taken on Polaroid type 52 film (Polaroid Corp., Cambridge, England) with UV haze and orange filters. The experiment was repeated twice on two replicate plates for each interaction. For each replicate, 10 agar blocks for each sampling time were examined using scanning electron microscopy (SEM).

Tissue processing for transmission electron microscopy. Mycelial samples $\left(2 \mathrm{~mm}^{3}\right)$ excised from the interaction were pre-embedded in $2 \%(\mathrm{wt} / \mathrm{vol})$ aqueous bacto-agar in order to preserve the hyphal population, and then immersed in $3 \%$ (vol/vol) glutaraldehyde in $0.1 \mathrm{M}$ sodium cacodylate buffer, $\mathrm{pH} 7.2$, for $2 \mathrm{~h}$ at room temperature. Samples were subsequently postfixed with $1 \%$ (wt/vol) osmium tetroxide in the same buffer for $1 \mathrm{~h}$ at $4^{\circ} \mathrm{C}$ and dehydrated in a graded ethanol series prior to embedding in Epon 812. Thin sections $(0.7 \mu \mathrm{m})$, cut from the Epon-embedded material using glass knives, were mounted on glass slides and stained with $1 \%$ aqueous toluidine blue prior to examination with a Zeiss Axioscope microscope (Carl Zeiss, Inc., Thornwood, NY). Ultrathin sections $(0.1 \mu \mathrm{m})$ were collected on Formvar-coated nickel grids and were either contrasted with uranyl acetate and lead citrate for direct examination with a JEOL 1200 EX electron microscope (JEOL, Ltd., Tokyo) operating at $80 \mathrm{kV}$ or processed for cytochemical labeling. An average of five samples from each sampling time were examined using five sections per sample.

Preparation of the colloidal gold probes. Colloidal gold with particles averaging $15 \mathrm{~nm}$ in diameter was prepared according to Frens (15) by reducing aqueous tetrachloroauric solution $(0.01 \%$ wt/vol) with $1 \%$ sodium citrate.

For the localization of cellulosic $\beta$-1,4-glucans, an exoglucanase ( $\beta$-1,4-D-glucan cellobiohydrolase, EC 3.2.1.21), purified from a cellulase produced by the fungus Trichoderma harzianum (4), was complexed to colloidal gold at $\mathrm{pH} 9.0$ and used in a one-step procedure, as previously described (4).

For chitin localization, wheat germ agglutinin (WGA), a lectin with $\mathrm{N}$-acetylglucosamine binding specificity, was used in a twostep procedure. Because of its low molecular weight, this lectin could not be directly complexed to colloidal gold. Ovomucoid, an egg white protein with WGA binding affinity, was used as a second-step reagent. It was conjugated to gold at $\mathrm{pH} 5.4$, according to a previously described procedure (2). The gold-complexed probes were stored at $4^{\circ} \mathrm{C}$ until use.

Cytochemical labeling. For labeling with the exoglucanase-gold complex, ultrathin sections, mounted on nickel grids, were first floated for $5 \mathrm{~min}$ on a drop of $0.01 \mathrm{M}$ sodium phosphate-buffered saline (PBS) containing $0.02 \%$ of polyethylene glycol (PEG) 20,000 at pH 6.0, corresponding to the optimal activity of the enzyme. Sections were then transferred to a drop of the gold-complexed enzyme for 30 to $60 \mathrm{~min}$ at room temperature in a moist chamber. They were washed thoroughly with PBS ( $\mathrm{pH} 7.4$ ), rinsed with distilled water, and allowed to dry before staining with uranyl acetate and lead citrate.

For labeling with the WGA-ovomucoid-gold complex, sections were first floated on a drop of PBS ( $\mathrm{pH} \mathrm{7.4)} \mathrm{for} 5 \mathrm{~min}$, and then transferred to a drop of WGA ( $25 \mu \mathrm{g} / \mathrm{ml}$ in PBS, $\mathrm{pH} 7.4)$ for $30 \mathrm{~min}$ at room temperature. Grids were thoroughly washed with PBS ( $\mathrm{pH}$ 7.4) and incubated on the ovomucoid-gold complex for $30 \mathrm{~min}$ at room temperature. Following washing with PBS and rinsing with distilled water, grids were counterstained with uranyl acetate and lead citrate.

Specificity of the labelings was assessed by the following control tests: (i) incubation with the gold-complexed exoglucanase to which was previously added the corresponding substrate $(\beta-1,4-$ glucans from barley, $1 \mathrm{mg} / \mathrm{ml}$ in PBS); (ii) incubation with the WGA to which was previously added an excess of $N-N^{\prime}-N^{\prime \prime}$-triacetylchitotriose, $1 \mathrm{mg} / \mathrm{ml}$ in PBS); (iii) incubation with WGA, followed by unlabeled ovomucoid and finally by ovomucoid-gold complex; (iv) substitution of the protein-gold complex under study by bovine serum albumin-gold complex to assess the nonspecific adsorption of the enzyme-gold complex to the tissue sections; and (v) incubation with stabilized or unstabilized gold suspension.

Reagents. The exoglucanase was provided by C. Breuil, Forintek, Canada. Tetrachloroauric acid was purchased from BDH Chemicals, Montreal, Canada. All other reagents for electron microscopy were obtained from JBEM Chemical Co., Pointe-Claire, Québec, Canada.

\section{RESULTS}

Mycelial interactions between $\boldsymbol{P}$. oligandrum and plant pathogens. In petri dish dual cultures, the first apparent contact between hyphae of $P$. oligandrum and those of $P$. ultimum, $P$. aphanidermatum, F. oxysporum f. sp. radicis-lycopersici, V. albo-atrum, and $R$. solani occurred within 2 to 3 days after inoculation. In the following days, $P$. oligandrum mycelium grew abundantly on hyphae of these plant pathogens and colonized the agar medium. When 
transferred to fresh medium, plant pathogen hyphae were unable to grow, while $P$. oligandrum mycelium developed abundantly. Contact between both partners in the $P$. oligandrum- $P$. megasperma interaction did not occur. As soon as 1 day after inoculation, Phytophthora growth was halted and changes in the hyphal morphology at the edge of the colony were observed visually.

Time-course investigation of cell-surface interactions. P. oligandrum-P. ultimum interaction. SEM examination of mycelial samples collected in the interaction region of 2-day-old dual cultures showed that hyphae of $P$. oligandrum, easily recognized by their smaller diameter (Fig. 1A), grew along the host hyphal walls and established tight binding (Fig. 1C). At this early state of parasitism, P. ultimum hyphae were turgescent and the integrity of the cell surface was similar to that observed in single cultures (Fig. 1B). By 3 days after inoculation, active growth of the antagonist was associated with pronounced host hyphal collapse and loss of turgor (Fig. 1D). Similar features of host cell alteration were observed in the case of $P$. aphanidermatum (data not shown).

P. oligandrum-F. oxysporum $f$. $s p$. radicis-lycopersici interaction. SEM observations of mycelial samples from the interaction region revealed that as soon as 2 days after inoculation the antagonist multiplied abundantly and coiled around the Fusarium hyphae (Fig. 1F, arrow). The coils were usually very dense and tightly encircled host hyphae, leading to strong hyphal compression, as illustrated by the wrinkled appearance of the cell surface (Fig. 1F) when compared with hyphae grown in single cultures (Fig. 1E). By 3 days after inoculation, coiling of $P$. oligandrum around the $F u$ sarium hyphae increased and signs of cell collapse were easily discernible (Fig. 1G). Tight coiling together with hyphal collapse were also typical features of reaction observed in the interaction between P. oligandrum and V. albo-atrum (data not shown).

P. oligandrum-R. solani interaction. At an early state of parasitism (2 days after inoculation), P. oligandrum hyphae established close contact with the host by means of frequent coiling around the hyphae (Fig. 1I). At this stage of the colonization process, no external damage was visible on the intertwined hyphae of $R$. solani, although some wrinkles could be seen at the hyphal surface (Fig. 1I). At a later stage of the interaction, both the plant pathogen and the antagonist appeared to suffer from some damage, mainly characterized by a marked loss of turgor and by obvious morphological alterations (Fig. 1J). By 3 days after inoculation, the Rhizoctonia hyphae were markedly collapsed, while cells of the antagonist exhibited pronounced signs of disorganization (Fig. 1K).

P. oligandrum-Phytophthora megasperma interaction. SEM investigation of mycelial samples collected at the edge of the pathogen colony showed that cells of the Phytophthora were seriously damaged at a time when contact between both the antagonist and the plant pathogen did not occur (Fig. 1L and M).

The different patterns of interaction between $P$. oligandrum and the plant pathogens under study indicated that the antagonism of $P$. oligandrum was not a simple process mediated by one single antimicrobial metabolite. Rather, the SEM observations suggested that each interaction was mediated by highly specific events that ultimately determined the outcome of the interaction. To gain a better insight into these specific events, more precise information at the ultrastructural level was needed.

Histological investigation of the cellular events involved in the interactions between $P$. oligandrum and plant pathogens. At the light microscope level, examination of samples from the interaction region between $P$. oligandrum and $P$. ultimum confirmed the SEM observations by providing evidence that the antagonist established close contact with the plant pathogen (Fig. 2B and C). Hyphae of $P$. oligandrum, easily recognizable by their smaller diameter, were closely appressed against hyphae of $P$. ultimum, which appeared highly vacuolated (Fig. 2B) as compared with hyphae grown in single cultures (Fig. 2A). Observations of the interaction region between $P$. oligandrum and $F$. oxysporum $\mathrm{f}$. sp. radicis-lycopersici revealed that most of the Fusarium hyphae
(80\%) were markedly damaged, as evidenced by the occurrence of numerous cells reduced to empty shells (Fig. 2E and F, arrowheads). Features of host penetration frequently were observed (Fig. 2E, arrows). The interaction between $P$. oligandrum and $R$. solani resulted in a cytoplasmic disorganization of most of the Rhizoctonia hyphae (80\%) (Fig. $2 \mathrm{H}$ to J). In addition to exhibiting strong morphological changes (Fig. 2J, arrow), most hyphae of the Rhizoctonia were stained less intensely with toluidine blue (Fig. $2 \mathrm{H}$ and I) than those grown in single cultures (Fig. 2G). By contrast, the thick host hyphal wall appeared well preserved and even, in some cases, reinforced by the deposition of a densely stained material (Fig. 2H, arrowhead). Leakage of the protoplasm often was seen in the vicinity of altered cells (Fig. 2J). Hyphae of $P$. oligandrum also showed obvious signs of alterations, mainly characterized by a more granular cytoplasm than normal (Fig. 2I). Cells of Phytophthora megasperma grown in dual cultures were altered markedly, as evidenced by a pronounced cytoplasm disorganization and, in some cases, by a complete loss of the protoplasm (Fig. $2 \mathrm{~L}$ and M).

Ultrastructural and cytochemical investigation of the cellular events involved in the interactions between $P$. oligandrum and plant pathogens. P. oligandrum-P. ultimum interaction. When grown in single cultures, Pythium hyphae showed an ultrastructure similar to that previously described (8). The protoplast was delimited by a thin cell wall and contained a dense, polyribosome-enriched cytoplasm in which a large number of organelles were found, including mitochondria, strands of endoplasmic reticulum, nuclei, and lipid bodies (Fig. 3A). Upon incubation of sections from these individual colonies of $P$. ultimum with the $\beta$-1,4-exoglucanase-gold complex for localizing cellulosic $\beta$-1,4-glucans, an intense labeling was associated specifically with the hyphal wall (data not shown).

Examination of 20 ultrathin sections from the interaction region of 2-day-old dual cultures showed that nearly all P. ultimum hyphae ( $90 \%)$ were encircled by hyphae of P. oligandrum (Fig. 3B). Although the structural integrity of $P$. ultimum protoplasm appeared intact, a close examination revealed a slight retraction of the plasmalemma from the wall (Fig. 3B, arrowheads). Alteration and distortion of the hyphal cell wall were visible at sites of potential penetration for the antagonist (Fig. 3B). Indeed, contact between both fungi was associated either with an apparent compaction of the wall layers (Fig. 3B, arrows) or with a disruption of the outermost wall layers (Fig. 3B, double arrows). A loosened network of fine fibrils was seen frequently when outer portions of the host cell wall were altered (Fig. 3B). Channels of antagonist penetration were usually narrower than the average hyphal diameter and were associated with slight wall dissolution as judged by the decrease in electron density in areas adjacent to penetration sites (Fig. 3B, double arrowheads).

By 3 days after inoculation, most cells of P. ultimum (nearly 95\%) appeared highly damaged as judged by the complete retraction or the rupture of the plasma membrane and by the pronounced cytoplasm aggregation (Fig. 3C). Organelles were no longer discernible in the highly altered cytoplasm (Fig. 3D). Close examination of contact areas showed that host penetration occurred through localized wall disruption (Fig. 3D, white arrow). Incubation with the goldcomplexed exoglucanase always resulted in a strong host wall labeling, except in the penetration areas of P. oligandrum (Fig. 3D).

At a more advanced stage of the antagonistic process, Pythium growth in host hyphae was very active and associated with marked host necrosis (Fig. 3E). Hyphae of the antagonist ramified so extensively in host hyphae that it was difficult to delineate some free space in the area that originally was occupied by the host cytoplasm (Fig. 3E). Such a massive colonization frequently resulted in a strong mechanical pressure against the host hyphal cell walls, ultimately leading to an apparent bursting of the host hyphae and to the release of actively multiplying $P$. oligandrum hyphae (Fig. 3E, arrows).

Cellular events associated with the interaction between $P$. oligandrum and $P$. aphanidermatum were similar to those observed with P. ultimum (Fig. 4). In all sections examined, active antagonist growth 

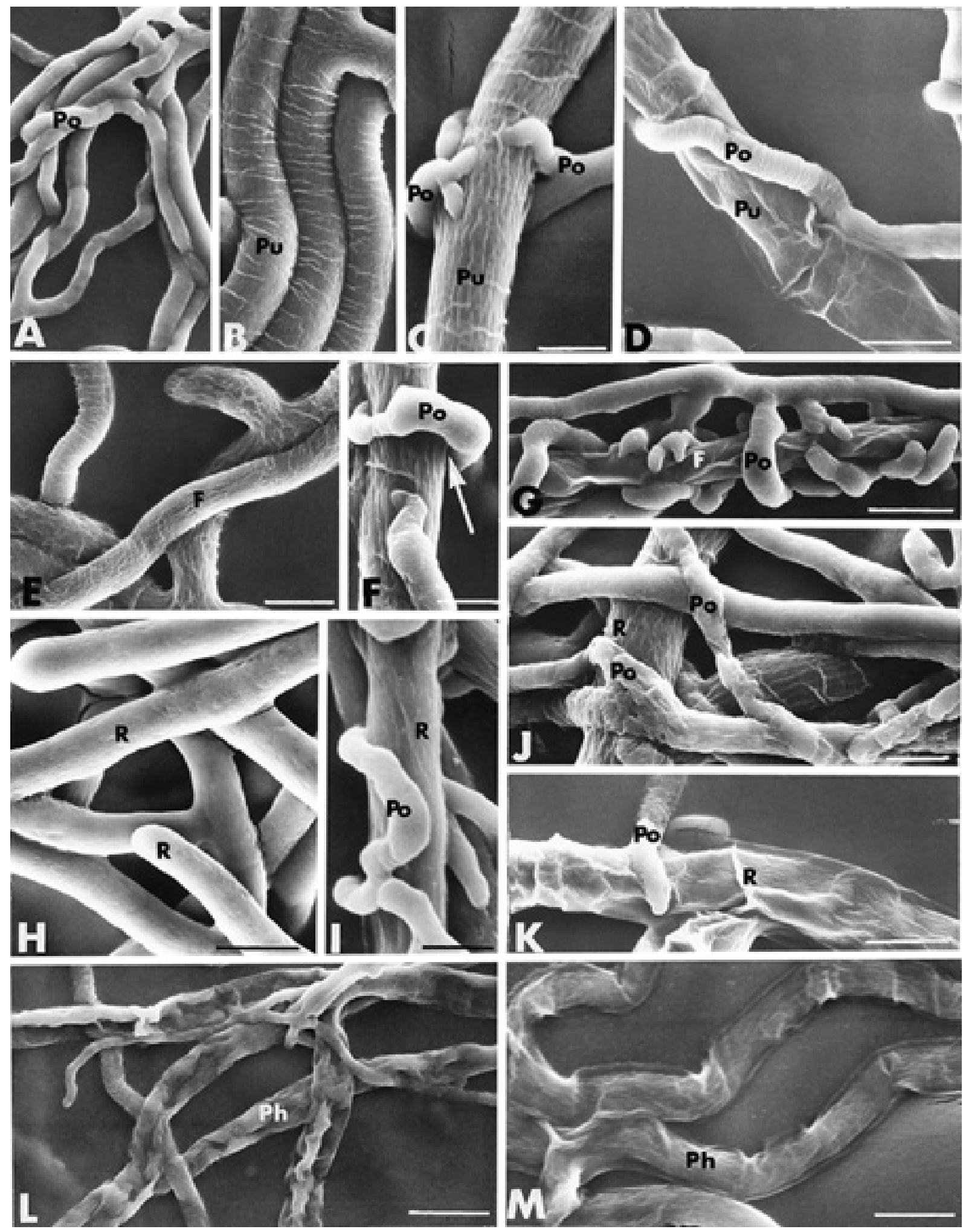

Fig. 1. Scanning electron micrographs of Pythium oligandrum hyphae interacting with hyphae of plant pathogens in dual cultures. A to D, P. oligandrum-P. ultimum interaction 2 to 3 days after inoculation. A, Hyphae of P. oligandrum (Po). Bar $=10 \mu \mathrm{m}$. B, Hyphae of P. ultimum $(\mathrm{Pu})$. Bar $=10 \mu \mathrm{m}$. C, P. oligandrum hyphae form dense coils and tightly encircle hyphae of P. ultimum. Bar $=5 \mu \mathrm{m}$. D, By 3 days after inoculation, active growth of the antagonist is associated with marked collapse and loss of turgor of $P$. ultimum hyphae. Bar $=10 \mu \mathrm{m}$. $\mathbf{E}$ to $\mathbf{G}$, P. oligandrum-Fusarium oxysporum f. sp. radicis-lycopersici interaction 2 to 3 days after inoculation. E, Fusarium (F) hyphae grown in single culture. Bar $=10 \mu \mathrm{m}$. F, Antagonist coils around the Fusarium hyphae. Coils are very dense and tightly encircle the host hyphae (arrow). Bar $=5 \mu \mathrm{m}$. G, By 3 days after inoculation, coiling of $P$. oligandrum around Fusarium hyphae increases and signs of cell collapse are discernible. Bar $=10 \mu \mathrm{m}$. $\mathbf{H}$ to $\mathbf{K}$, P. oligandrum-Rhizoctonia solani interaction 2 to 3 days after inoculation. $\mathbf{H}$, Rhizoctonia (R) hyphae grown in single culture. Bar $=8 \mu \mathrm{m}$. I, P. oligandrum hyphae establish close contact with the host by means of coiling. Bar $=5 \mu \mathrm{m}$. J and $\mathbf{K}$, By 3 days after inoculation, both the host (R) and the antagonist (Po) suffer from some damage characterized by a marked loss of turgor and a pronounced collapse. $\mathrm{J}$, Bar $=5 \mu \mathrm{m}$; and $\mathrm{K}$, bar $=6 \mu \mathrm{m})$. $\mathbf{L}$ and $\mathbf{M}$, P. oligandrum-Phytophthora megasperma interaction 2 to 3 days after inoculation. Phytophthora $(\mathrm{Ph}) \mathrm{hyphae}$ are seriously damaged, while contact between the antagonist and the pathogen does not occur. L, Bar $=10 \mu \mathrm{m}$; and $\mathrm{M}$, bar $=5 \mu \mathrm{m}$. 


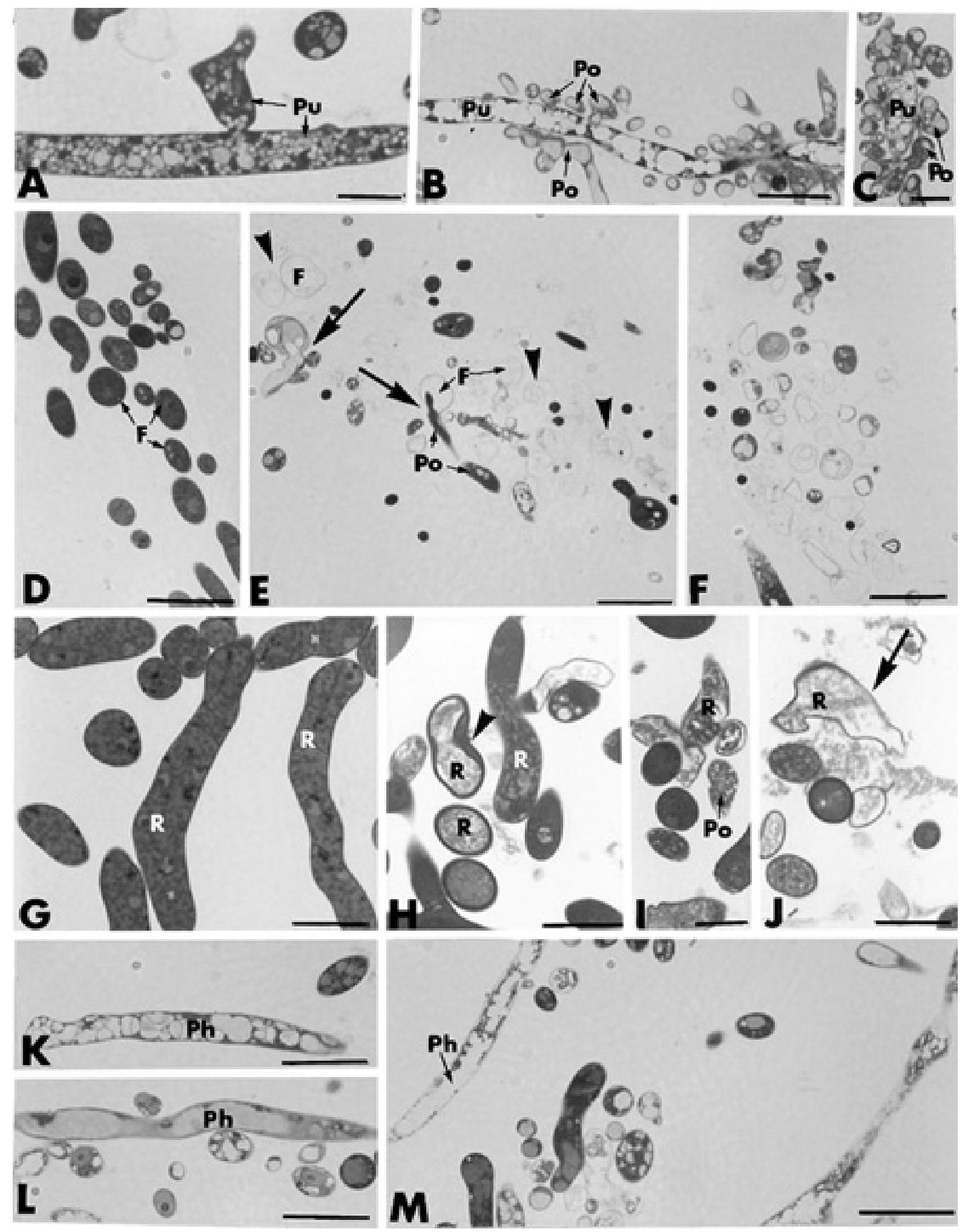

Fig. 2. Light micrographs of sectioned mycelial samples collected 2 to 3 days after inoculation in the interaction region between Pythium oligandrum and plant pathogens. Staining with toluidine blue. A to $\mathbf{C}, P$. oligandrum-P. ultimum interaction 2 to 3 days after inoculation. A, Hyphae of $P$. ultimum (Pu) grown in single culture. Bar $=10 \mu \mathrm{m}$. B and C, Hyphae of $P$. oligandrum (Po), easily recognizable by their smaller diameter, are closely appressed against cells of $P$. ultimum, which appear highly vacuolated. B, Bar $=20 \mu \mathrm{m}$; and C, bar $=10 \mu \mathrm{m}$. D to F, P. oligandrum-Fusarium oxysporum f. sp. radicis-lycopersici interaction 2 to 3 days after inoculation. Bars $=10 \mu \mathrm{m}$. D, Fusarium (F) hyphae grown in single culture. E and F, Fusarium hyphae are markedly damaged, as evidenced by the occurrence of numerous cells reduced to empty shells (arrowheads). Features of host penetration are observed (arrows). G to J, P. oligandrumRhizoctonia solani interaction 2 to 3 days after inoculation $\mathbf{G}$, Hyphae of $R$. solani $(\mathrm{R})$ grown in single culture. Bar $=10 \mu \mathrm{m}$. $\mathbf{H}$ to $\mathbf{J}$, Hyphae of Rhizoctonia are stained less intensely with toluidine blue than $\mathbf{J}$, those grown in single cultures (arrow). The thick host cell wall appears well preserved and, in some cases, reinforced by $\mathbf{H}$, the deposition of a densely stained material (arrowhead). H, Bar $=10 \mu \mathrm{m} ; \mathrm{I}$, bar $=5 \mu \mathrm{m}$; and $\mathbf{J}$, bar $=10 \mu \mathrm{m}$. I, Leakage of the host protoplasm is seen in the vicinity of altered cells. Hyphae of $P$. oligandrum show signs of alterations, characterized by a more granular cytoplasm than normal. K to $\mathbf{M}, P$. oligandrum-Phytophthora megasperma interaction 2 to 3 days after inoculation. Bars $=10 \mu \mathrm{m}$. $\mathbf{K}$, Hyphae of $P$. megasperma $(\mathrm{Ph})$ grown in single culture. $\mathbf{L}$ and M, Cells of Phytophthora megasperma are markedly altered as evidenced by a pronounced cytoplasm disorganization and an increased vaculoation. 


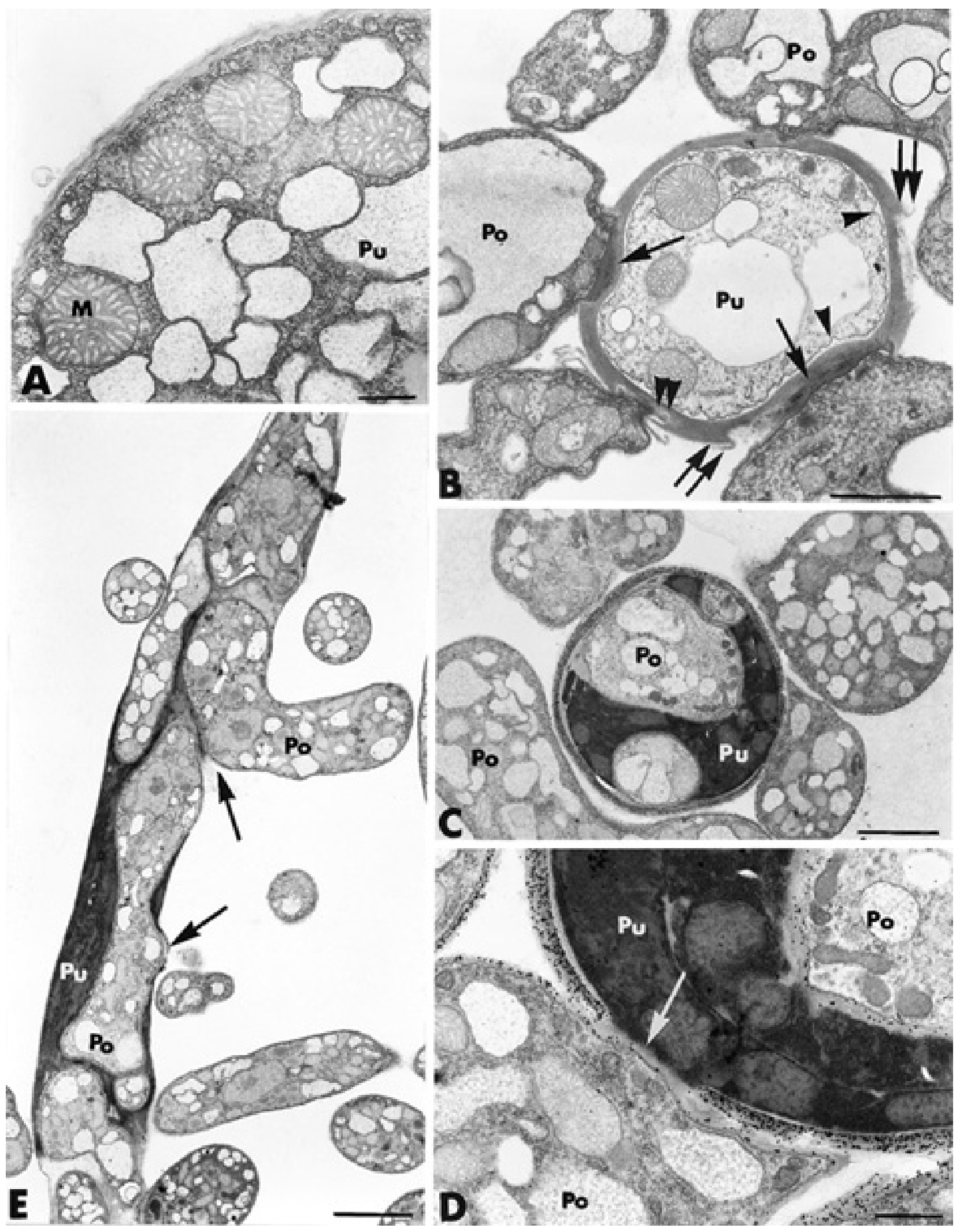

Fig. 3. Transmission electron micrographs of mycelial samples collected 2 days after inoculation in the interaction region between Pythium oligandrum and $P$. ultimum. A, P. ultimum grown in single culture. The cell is metabolically active as judged by the presence of mitochondria $(\mathrm{M})$. Bar $=0.5 \mu \mathrm{m}$. B, A hypha of $P$. ultimum $(\mathrm{Pu})$ is encircled by hyphae of $P$. oligandrum $(\mathrm{Po})$. A slight retraction of the plasmalemma from the wall is visible (arrowheads). Contact between the antagonist and the host is either associated with an apparent compaction of the wall layers (arrows) or with a disruption of the outermost wall layers (double arrows). A slight wall dissolution is seen in areas adjacent to the sites of penetration (double arrowheads). Bar $=1 \mu \mathrm{m}$. $\mathbf{C}$, Cytoplasm aggregation and plasma membrane retraction are typical features of host reaction upon antagonist invasion. Bar $=1.5 \mu \mathrm{m}$. D, Host penetration occurs through localized wall disruption (white arrow). Incubation with the gold-complexed exoglucanase results in a strong host wall labeling, except in the areas of $P$. oligandrum $(\mathrm{Po})$ penetration. Bar $=0.5 \mu \mathrm{m}$. E, By 3 days after inoculation, growth of $P$. oligandrum in the host hyphae is very active and associated with marked host cell necrosis. The massive colonization results in a strong mechanical pressure against the host hyphal cell walls, ultimately leading to the release of the actively multiplying $P$. oligandrum hyphae (arrows). $B a r=2 \mu \mathrm{m}$. 
in the host hyphae resulted in a complete disorganization of cytoplasm and in the release of the protoplasm through local perforations (Fig. 4A and B, arrow). At an advanced stage of the colonization process, hyphae of $P$. aphanidermatum were reduced to ghost hyphae in which some labeled wall remnants were indicative of the former presence of a fungal protoplasm (Fig. 4C).

P. oligandrum-F. oxysporum $f$. $s p$. radicis-lycopersici interaction. The Fusarium hyphae grown in single cultures displayed a normal appearance with a thin wall and a dense cytoplasm containing numerous organelles, as well as Woronin bodies in the septum area (Fig. 5A). As early as 2 days after inoculation in dual cultures, close interaction between $P$. oligandrum and the Fusarium hyphae was observed and contact appeared to be mediated by an amorphous matrix in which some electron-dense inclusions were embedded (Fig. 5B). Upon application of the WGA-ovomucoid-gold complex for the localization of chitin molecules, a strong deposition of gold particles occurred over both the host cell walls and the connecting matrix (Fig. 5C). By contrast, the presence of cellulose, as determined by labeling with the gold-complexed exoglucanase, was not detected in the matrix, while this compound was specifically associated with the hyphal walls of P. oligandrum (Fig. 5D).

By 3 days after inoculation, cells of $P$. oligandrum multiplied actively and frequently penetrated the Fusarium hyphae (Fig. 5E). Pythium ingress in host hyphae coincided with extensive cell altera- tions, leading to cytoplasm breakdown and organelle disintegration (Fig. 5E). At this stage of invasion, host cell walls were disrupted in places likely corresponding to antagonist penetration.

At a later stage of the colonization process, active growth of the antagonist in the host hyphae resulted in an apparent mechanical pressure against the host hyphal walls, leading to complete $F u$ sarium cell breakdown (Fig. 5F, arrows). Actively multiplying $P y$ thium hyphae, easily recognizable by their walls specifically labeled with the exoglucanase-gold complex, escaped from moribund the Fusarium hyphae to colonize new host cells (Fig. 5G).

P. oligandrum-R. solani interaction. Observations of samples from colonies of $R$. solani grown in single cultures showed the presence of a dense, regularly septate mycelium composed of branched hyphae surrounded by a thick wall (Fig. 6A). By 2 days after inoculation in dual cultures, structural changes were observed in several $R$. solani hyphae ( $60 \%$ of the examined cells). Such changes, mainly characterized by a splitting of the host cell wall, usually were restricted to well-delineated areas, apparently corresponding to sites of antagonist contact (Fig. 6B). A granular material containing electron-dense inclusions was found to accumulate between the split walls (Fig. 6B). At that stage of the interaction, no modification of the host cytoplasm or the plasma membrane and the organelles was observed. By contrast, most hyphae $(\sim 50 \%)$ of the antagonist appeared distorted and swollen. Upon incubation with

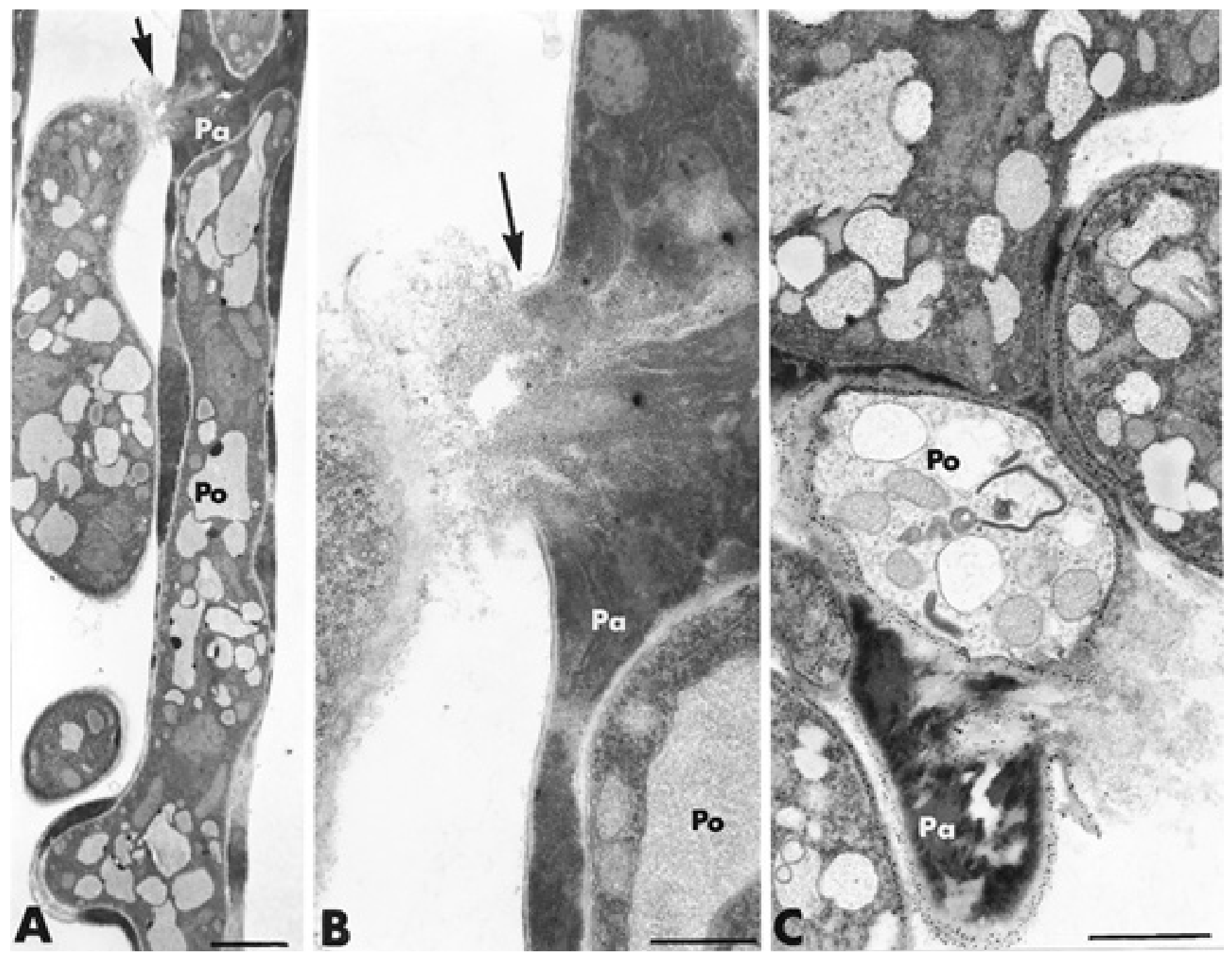

Fig. 4. Transmission electron micrographs of mycelial samples collected 2 days after inoculation in the interaction region between Pythium oligandrum (Po) and $P$. aphanidermatum $(\mathrm{Pa})$. A to $\mathbf{C}$, Active growth of the antagonist $(\mathrm{Po})$ in the host hyphae $(\mathrm{Pa})$ results in a complete disorganization of the cytoplasm and in $\mathbf{A}$ and $\mathbf{B}$, the release of the protoplasm through local perforations (arrows). A, Bar $=2 \mu \mathrm{m}$; and $\mathrm{B}, \mathrm{bar}=0.6 \mu \mathrm{m}$. $\mathbf{C}$, At an advanced stage of the colonization process, a hypha of $P$. aphanidermatum is reduced to a ghost cell. Bar $=1 \mu \mathrm{m}$. 

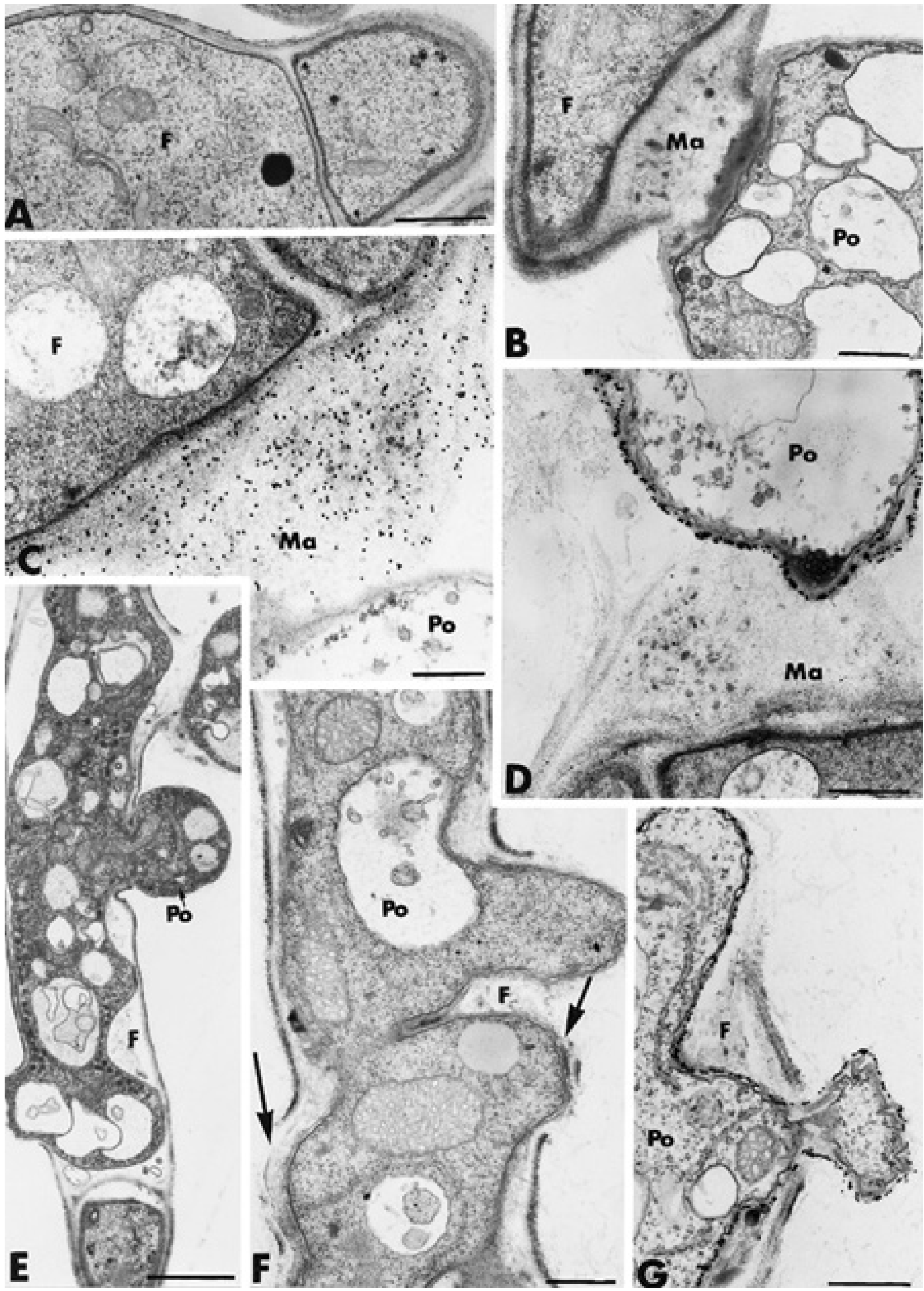

Fig. 5. Transmission electron micrographs of mycelial samples collected 2 days after inoculation in the interaction region between Pythium oligandrum and Fusarium oxysporum f. sp. radicis-lycopersici. A, Fusarium $(\mathrm{F})$ hyphae grown in single culture. Bar $=0.7 \mu \mathrm{m}$. B to D, By 2 days after inoculation in dual cultures, close interaction between P. oligandrum (Po) and Fusarium hyphae is observed and contact is mediated by an amorphous matrix (Ma) that is C, labeled by the wheat germ agglutinin-ovomucoid-gold complex for the localization of chitin molecules and $\mathbf{D}$, unlabeled with the gold-complexed exoglucanase for the localization of cellulose subunits. B, Bar $=0.5 \mu \mathrm{m} ; \mathrm{C}$, bar $=0.4 \mu \mathrm{m}$; and D, bar $=0.5 \mu \mathrm{m}$. $\mathbf{E}$ and $\mathbf{F}$, By 3 days after inoculation, cells of $P$. oligandrum multiply actively and E, penetrate Fusarium hyphae, causing extensive cell alterations and F, host cell wall breakdown (arrows). E, Bar $=1 \mu \mathrm{m}$; and F, bar $=0.4 \mu \mathrm{m}$. G, Actively multiplying Pythium hyphae, recognizable by their walls labeled with the exoglucanase-gold complex, escape from moribund Fusarium hypha. Bar $=0.5 \mu \mathrm{m}$. 


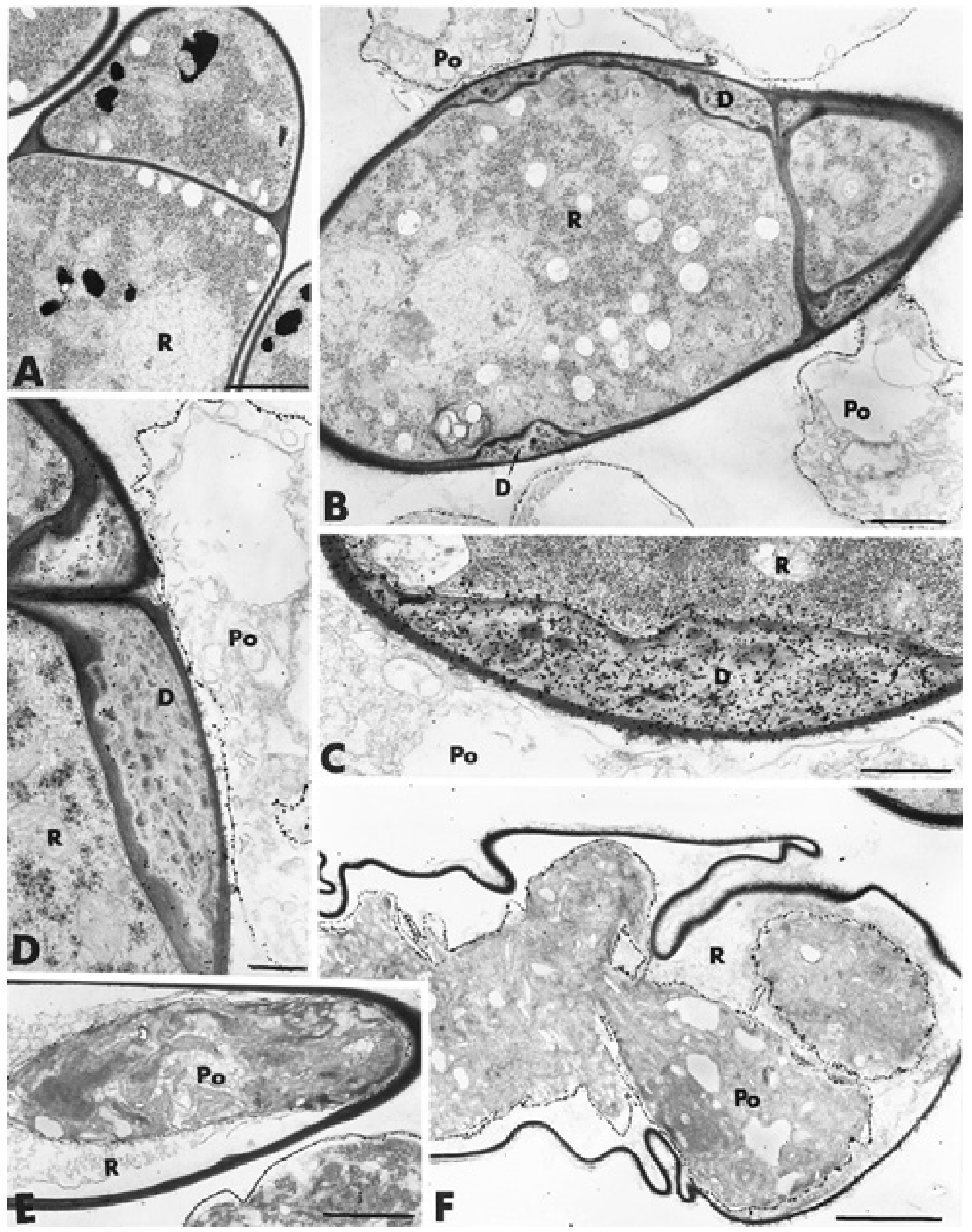

Fig. 6. Transmission electron micrographs of mycelial samples collected 2 days after inoculation in the interaction region between Pythium oligandrum and Rhizoctonia solani. A, Rhizoctonia $(\mathrm{R})$ hyphae grown in single culture. Bar $=1 \mu \mathrm{m}$. B to $\mathbf{D}$, By 2 days after inoculation in dual cultures, splitting of the host cell wall occurs at sites of contact with the antagonist (Po). Cells of P. oligandrum (Po) are distorted and swollen. The deposited material (D) is $\mathbf{C}$, intensely labeled with the wheat germ agglutinin-ovomucoid-gold complex and $\mathbf{D}$, slightly labeled with the gold-complexed exoglucanase. B, Bar $=1 \mu \mathrm{m} ; \mathrm{C}$, bar $=0.4 \mu \mathrm{m} ;$ and $\mathrm{D}$, bar $=0.5 \mu \mathrm{m} ; \mathbf{E}$ and $\mathbf{F}$, By 3 days after inoculation, $R$. solani hyphae are invaded by the antagonist and exhibit pronounced disorganization such as $\mathbf{E}$, cytoplasm disintegration and $\mathbf{F}$, wall distortion. Morphological alterations are also observed over hyphae of $P$. oligandrum. $\mathrm{E}, \mathrm{Bar}=1.5 \mu \mathrm{m}$; and $\mathrm{F}, \mathrm{bar}=1.5 \mu \mathrm{m}$. 
the WGA-ovomucoid-gold complex, the deposited material was found to be markedly enriched with chitin (Fig. 6C), whereas cellulose appeared to be a minor component (Fig. 6D).

At a more advanced stage of the colonization process, hyphae of $R$. solani were altered severely. Pronounced structural modifications, including cytoplasm disintegration and wall distortion, were observed (Fig. 6E and F). Although features of host penetration could not be seen in the examined samples, cells of the antagonist, easily recognizable by the regular labeling of their walls with the gold-complexed exoglucanase, frequently were seen inside the Rhizoctonia hyphae. However, these invading hyphae of the antagonist appeared morphologically and structurally damaged (Fig. 6F).

P. oligandrum-Phytophthora megasperma interaction. In single cultures, hyphae of $P$. megasperma were surrounded by a thick, wavy wall and contained a polyribosome-rich cytoplasm with numerous organelles (Fig. 7A). From 2 to 4 days after inoculation in dual cultures, considerable changes in the structural cell organization could be noticed. Although contact with the antagonist did not occur, all Phytophthora hyphae exhibited a markedly altered content. In most cases, the cytoplasm was reduced to some aggregated or vesicular remnants (Fig. 7B). By contrast, the wall structure appeared preserved, as judged by the regular labeling obtained with the exoglucanase-gold complex (Fig. 7C).

All control tests, including previous adsorption of the gold-complexed probes with their corresponding substrate molecules, yielded negative results (data not shown).

\section{DISCUSSION}

Results of the current study demonstrate that all pathogenic oomycetes and true fungi under study are highly vulnerable to an attack by the antagonistic fungus $P$. oligandrum, strain 1010 . These results agree with earlier reports on the potential of $P$. oligandrum to cause adverse effects on a wide range of plant pathogens $(7,11)$ and provide the first ultrastructural and cytochemical evidence that antagonism is a multifaceted process dependent on the target species involved. According to our observations, at least two distinct mechanisms are involved in the process of fungal attack by $P$. oligandrum: (i) mycoparasitism, mediated by intimate hyphal interactions, and (ii) antibiosis, with alteration of the host hyphae prior to contact with the antagonist. Although attachment and local antagonist penetration into pathogen hyphae were common features observed during mycoparasitism, clear differences in host responses to penetration by the antagonist were noticed, suggesting that molecular exchanges between both partners determine the outcome of a given interaction. In that context, three different patterns of host reactions were observed: (i) aggregation of the host cytoplasm followed by necrotization of hyphae and extrusion of cell content $(P$. ultimum and $P$. aphanidermatum); (ii) rapid lysis of the host cytoplasm and cell wall disruption leading to complete host cell breakdown ( $F$. oxysporum f. sp. radicis-lycopersici and V. albo-atrum); and (iii) induction of a host structural response at potential entry sites for the antagonist, followed by alteration of both host and antagonist hyphae ( $R$. solani), in a way similar to a mutually antagonistic mechanism.

Macroscopic observations of fungal development in dual cultures as well as SEM investigations of interaction regions demonstrated that growth inhibition and structural alterations of all plant pathogens except Phytophthora started to appear soon after contact with hyphae of $P$. oligandrum. These observations provided support to the assumption that the outcome of the interactions likely was determined by early recognitional events that triggered firm
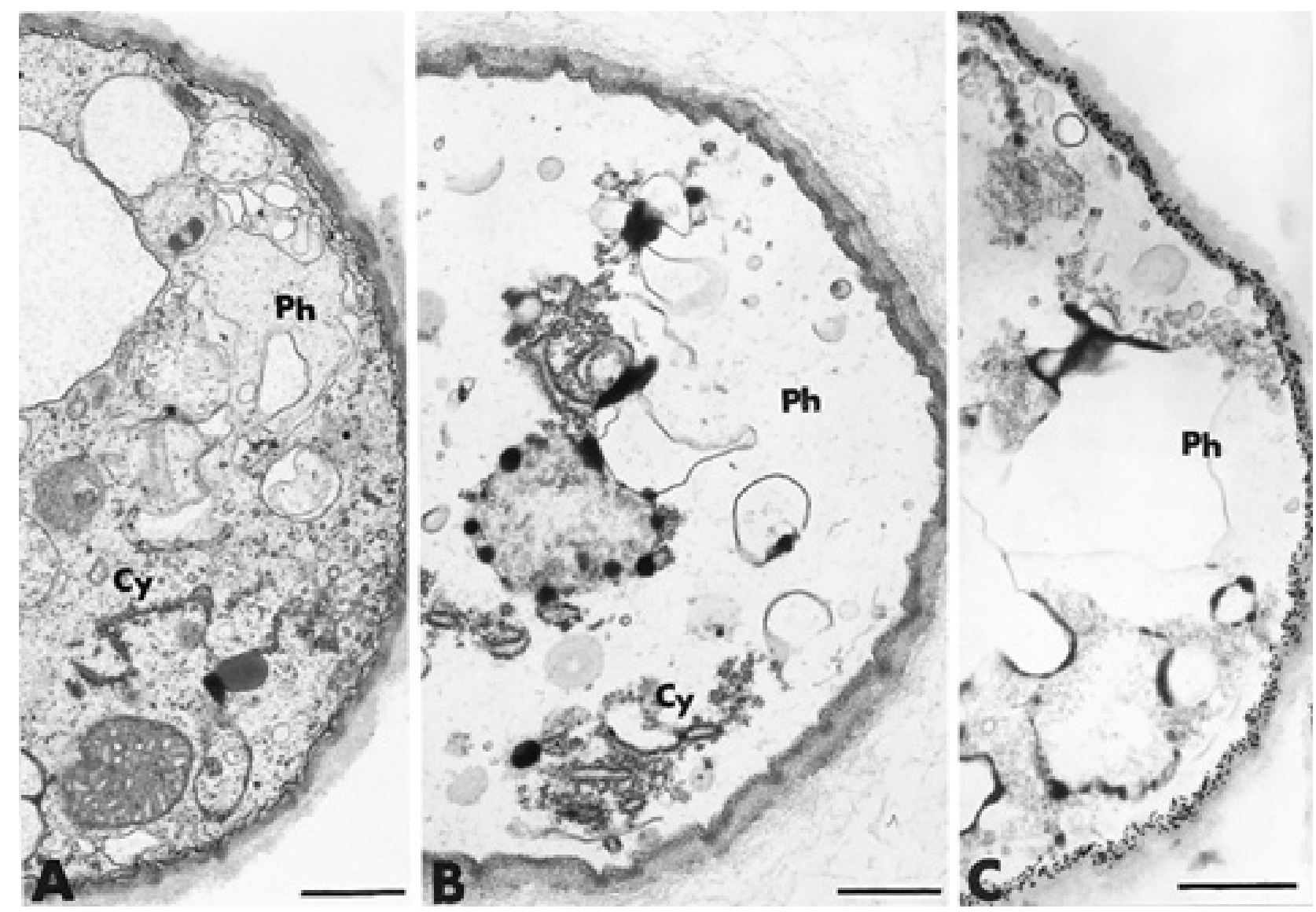

Fig. 7. Transmission electron micrographs of mycelial samples collected 2 days after inoculation in the interaction region between Pythium oligandrum and Phytophthora megasperma. A, Phytophthora hyphae ( $\mathrm{Ph})$ grown in single cultures. Bar $=0.5 \mu \mathrm{m}$. B and $\mathbf{C}$, In dual cultures, the host cytoplasm (Cy) is reduced to some aggregated or vesicular remnants. By contrast, the wall structure is preserved as judged by $\mathbf{C}$, the regular labeling obtained with the exoglucanase-gold complex. B, Bar $=0.5 \mu \mathrm{m}$; and $\mathrm{C}$, bar $=0.6 \mu \mathrm{m}$. 
antagonist binding to the host cell surface, leading to subsequent responses such as adhesion, coiling, and host penetration. Positive correlations between surface-associated components and recognition events in microbial interactions often have been suggested $(5,9)$ and considered to be key determinants in the outcome of a given interaction. Although early studies pointed to a possible role for lectins in the recognition process, only recently did Inbar and Chet (18) prove the role of lectins in Trichoderma mycoparasitism. Using lectin-coated nylon fibers, they demonstrated that $T$. harzianum coiled around the fibers in a way similar to that observed with host hyphae. Whether such a phenomenon plays a role in the initial recognition between $P$. oligandrum and its hosts, including $P$. ultimum, F. oxysporum f. sp. radicis-lycopersici, and $R$. solani, warrants further investigation. However, the observation that firm adhesion, often mediated by branched $P$. oligandrum hyphae (Fig. 1C and G), preceded host hyphal collapse favors the assumption that specific molecular interactions occurred at the cell surface and determined a host recognition response that, in turn, triggered a series of events leading to penetration and invasion by the antagonist. In line with this concept, observations of the interaction region between $P$. oligandrum and $F$. oxysporum f. sp. radicislycopersici showed that contact apparently was mediated by a fine, external matrix originating from the Fusarium hyphae (Fig. 5C and D). The occurrence of a significant amount of chitin residues in this matrix suggests that receptors with $N$-acetylglucosaminebinding affinity are present at the cell surface of $P$. oligandrum. A similar interfacial material was not detected in the interactions between the antagonist and $P$. ultimum, $P$. aphanidermatum, or $R$. solani, although intense coiling and adhesion of $P$. oligandrum to the host hyphae could be seen. $P$. ultimum and $P$. aphanidermatum are oomycetes, known to contain cellulose as the main wall-bound component; therefore, it is unlikely that $\mathrm{N}$-acetylglucosamine-binding receptors are involved in the recognition events with the antagonist. This raises the question as to which extent more than one type of receptors is involved in the binding process between $P$. oligandrum and its hosts. While it is obvious that $P$. oligandrum is an aggressive mycoparasite with a wide host range, our knowledge of the actual mechanisms operating in the initial events of each interaction remains rudimentary.

Light and transmission electron microscopy investigations of the interaction region between $P$. oligandrum and $P$. ultimum showed that hyphae of the antagonist established intimate contact with the host within 2 days postinoculation. Following adhesion of $P$. oligandrum hyphae to hyphae of $P$. ultimum, a series of degradation events, mainly characterized by a marked aggregation of the host cytoplasm associated with an alteration of all organelles, was observed. In addition, the cellulose component of the host wall was altered at sites of potential penetration (Fig. 3D, arrow). This obviously implies that at least small amounts of cell wall hydrolytic enzymes such as cellulases are produced by the mycoparasite to weaken locally or loosen the host wall, thus facilitating spread into host hyphae. Production of extracellular lytic enzymes by $P$. oligandrum is a well-documented phenomenon (22) that long has been thought to be involved in the process of hyphal penetration. However, even though several hydrolytic enzymes including proteases, lipases, and $\beta$-1,3-glucanases have been shown to be produced in liquid cultures containing hyphal walls as the sole carbon sources, cellulases never could be detected in culture media containing cellulose or methyl cellulose as substrates, thus leading to the concept of the noncellulolytic nature of P. oligandrum $(11,22)$. Our results provide the first conclusive evidence that cellulose hydrolysis is one of the mechanisms involved in the antagonistic process exerted by $P$. oligandrum against $P$. ultimum and $P$. aphanidermatum. This crucial observation suggests that cellulase synthesis by $P$. oligandrum is a phenomenon induced in response to a signal produced by the pathogen itself. In all examined samples, host cell penetration by the antagonist seldom was associated with host cell wall breakdown. This was corroborated by the labeling pat- tern of cellulose that showed that, except in the area of antagonist penetration, the cellulose component of the host cell walls was structurally preserved, even at a time when the host cytoplasm had undergone complete disorganization. The observed structural changes such as plasmalemma retraction and cytoplasm aggregation are reminiscent of the disturbances detected in fungal cells exposed to antibiotics $(1,20)$. These results tend to indicate that antibiosis causing cytoplasm disintegration precedes or coincides with parasitism and subsequent internal colonization of host hyphae.

Ultrastructural observations of sections from parasitized $\mathrm{Fu}$ sarium hyphae provided evidence that antagonist penetration was associated with degradation events including retraction of the plasmalemma, disorganization of the cytoplasm, and ultimately complete loss of the protoplasm. These results confirm earlier observations on the ability of $P$. oligandrum to induce pronounced cytoplasmic damage upon host invasion (6). Host cytoplasmic disorganization often occurred in advance of penetration, suggesting that diffusible compounds were responsible for the observed disturbances. Penetration of the antagonist occurred through localized hyphal wall disruption, indicating that at least small amounts of chitinases were produced. This observation again contrasts with that of Lewis et al. (22), who could not detect chitinases in liquid cultures amended with host cell walls, and suggests that chitinase production is an inducible phenomenon in the presence of the pathogen only. The active growth of $P$. oligandrum in the Fusarium hyphae was accompanied by an apparent mechanical pressure leading to hyphal burst of the host (Fig. 5F).

Currently, the production of cell wall lytic enzymes by $P$. oligandrum is not clearly defined and further biochemical investigations are required to provide precise information on this mechanism. The finding that cellulose and chitin still occurred over the walls of hyphae of Pythium and Fusarium showing signs of pronounced disorganization suggests that cellulolytic and chitinolytic enzymes are not the only critical mechanisms involved in the antagonism exerted by $P$. oligandrum. Although it is clear that such enzymes are produced and play a key role in breaching the host walls at sites of attempted penetration, it seems likely that further enzymatic production contributes more to the saprophytic phase of the antagonist when the main wall-bound compounds are utilized as a food source providing the energy required for growth.

Hyphae of $P$. oligandrum were found to rapidly establish contact with the Rhizoctonia hyphae. One of the most prominent facets of this early stage of the interaction between both microorganisms was the abnormal deposition of an amorphous wall-like material at sites of potential penetration for the antagonist. Such deposits were subtended by deeply invaginated areas of the host plasma membrane and contained large amounts of chitin. The mechanisms that control the process of chitin deposition at such sites is unclear, although at least two explanations may be advanced. First, the accumulating material may originate from the host cell wall through the swelling and stretching of preexisting polymers. This obviously would require the action of chitinases produced by the antagonist and would imply a subsequent decrease in the wallbound chitin compounds in the Rhizoctonia hyphae. However, at that time after inoculation, we did not observe marked alterations of the Rhizoctonia cell walls or substantial differences in the intensity of chitin labeling as compared with control hyphae grown in single cultures. Second, the deposited material may be laid down as newly synthesized molecules. This possibility raises the question of how the Rhizoctonia hyphae can regulate the deposition of wall-like material in unusual cell areas. Membrane-bound proteins such as enzymes involved in the synthesis of structural compounds are known to be linked to lipids, which play a major role in regulating the permeability of the plasma membrane $(25,28)$. Alteration in the lipid composition of the plasma membrane of $R$. solani hyphae, possibly resulting from the action of toxic compounds produced by $P$. oligandrum, may therefore induce a deregulation of membrane-bound enzymes, resulting in areas of abnormal wall- 
like deposition. In line with this hypothesis, previous reports have shown that fungal cell treatment with some fungicides (26) or with chitosan (3) could affect the fluidity and the permeability of the plasma membrane, leading to changes in the biological activity of membrane enzymes and to the accumulation of newly formed material at sites where deposition of wall polymers normally does not occur. The exact biological function played by the chitin-rich deposits is not understood, but one may speculate that the massive accumulation of structural compounds at unusual sites reflects a defense strategy elaborated by $R$. solani cells for preventing penetration of the antagonist.

Whatever the role played by the deposited material, the antagonist displayed the ability to circumvent this barrier by altering its structure, as exemplified by the invasion of most $R$. solani hyphae by numerous hyphae of the antagonist (Fig. 6F). This again indicates the potential of $P$. oligandrum to produce chitinolytic enzymes and raises the question as to what extent weakening of the cell wall through the action of $P$. oligandrum chitinases may facilitate the diffusion of toxic compounds toward membrane receptors by increasing the wall permeability. In a recent study, Di Pietro et al. (13) reported that the synergistic action of hydrolytic enzymes (mainly chitinases) and antibiotics was required in the biocontrol process mediated by $G$. virens. They suggested that both mechanisms were expressed in a controlled sequence and that slight alterations of the host cell walls were essential prerequisites for further antibiotic diffusion. The production of toxic compounds by $P$. oligandrum was further corroborated by the observation that cytoplasmic disorganization in the Phytophthora hyphae occurred in the absence of physical contact with the antagonist. Indeed, while features of coiling and hyphal invasion were never observed in the interaction between P. oligandrum and Phytophthora megasperma, typical disturbances such as retraction and aggregation of the host cytoplasm were taken as an indication that diffusible compounds were released in the culture medium and infiltrated hyphae of the pathogen, causing damages similar to those induced by fungicides.

Although the mechanisms by which $P$. oligandrum operates differ according to the host species, evidence is provided from the current results that antibiosis is a common feature of the antagonism. In line with this concept, an elicitin-like molecule has been recently isolated from culture filtrates of $P$. oligandrum and identified as a low-molecular-weight protein (K. Picard, P. Rey, N. Benhamou, and Y. Tirilly, unpublished data). Bioassays are currently being undertaken to confirm the antimicrobial properties of this protein and its potential involvement in the antagonistic process.

\section{ACKNOWLEDGMENTS}

This research was supported by grants from the Fonds Québécois pour la formation de chercheurs et l'Aide à la Recherche (FCAR) and the Natural Sciences and Engineering Council of Canada (NSERC). We thank A. Goulet and C. Garand for excellent technical assistance and J. Hockenhull (Department of Plant Biology, The Royal Veterinary and Agricultural University, Copenhagen, Denmark) for providing the strain of Pythium oligandrum.

\section{LITERATURE CITED}

1. Bélanger, R. R., Dufour, N., Caron, J., and Benhamou, N. 1995. Chronological events associated with the antagonistic properties of Trichoderma harzianum against Botrytis cinerea: Indirect evidence for sequential role of antibiosis and parasitism. Biocontrol Sci. Technol. 5:41-53.

2. Benhamou, N. 1989. Preparation and applications of lectin-gold complexes. Pages 95-143 in: Colloidal Gold, Principles, Methods and Applications, Vol. 1. M. A. Hayat, ed. Academic Press, New York.

3. Benhamou, N. 1992. Ultrastructural and cytochemical aspects of chitosan on Fusarium oxysporum f. sp. radicis-lycopersici, agent of tomato crown and root rot. Phytopathology 82:1185-1193.

4. Benhamou, N., Chamberland, H., Ouellette, G. B., and Pauzé, F. J. 1987.
Ultrastructural localization of $\beta$-1,4-D-glucans in two pathogenic fungi and in their host tissues by means of an exoglucanase-gold complex. Can. J. Microbiol. 33:405-417.

5. Benhamou, N., and Chet, I. 1993. Hyphal interactions between Trichoderma harzianum and Rhizoctonia solani: Ultrastructure and gold cytochemistry of the mycoparasitic process. Phytopathology 83:1062-1071.

6. Benhamou, N., Rey, P., Chérif, M., Hockenhull, J., and Tirilly, Y. 1997. Treatment with the mycoparasite, Pythium oligandrum, triggers the induction of defense-related reactions in tomato roots upon challenge with $\mathrm{Fu}$ sarium oxysporum $\mathrm{f}$. sp. radicis-lycopersici. Phytopathology 87:108-122.

7. Berry, L. A., Jones, E. E., and Deacon, J. W. 1993. Interaction of the mycoparasite Pythium oligandrum with other Pythium species. Biocontrol Sci. Technol. 3:247-260.

8. Bradshaw-Smith, R. P., Whalley, W. M., and Craig, G. D. 1991. Interactions between Pythium oligandrum and the fungal footrot pathogens of peas. Mycol. Res. 95:861-865.

9. Chet, I. 1987. Trichoderma-Applications, mode of action and potential as a biocontrol agent of soilborne plant pathogenic fungi. Pages 137-160 in: Innovative Approaches to Plant Diseases. I. Chet, ed. John Wiley \& Sons, New York.

10. Chet, I., and Inbar, J. 1994. Biological control of fungal pathogens. Appl. Biochem. Biotechnol. 48:37-43.

11. Deacon, J. W. 1976. Studies on Pythium oligandrum, an aggressive parasite of other fungi. Trans. Br. Mycol. Soc. 66:383-391.

12. Devaki, N. S., Shankara, S., Bhat, S. G., and Manjunatha, K. R. 1992. Antagonist activities of Trichoderma harzianum against Pythium aphanidermatum and Pythium myriotylum on tobacco. J. Phytopathol. 136:82-87.

13. Di Pietro, A., Lorito, M., Hayes, C. K., Broadway, R. M., and Harman, G. E. 1993. Endochitinases from Gliocladium virens: Isolation, characterization, and synergistic antifungal activity in combination with gliotoxin. Phytopathology 83:308-313.

14. Foley, M. F., and Deacon, J. W. 1986. Susceptibility of Pythium species and other fungi to antagonism by the mycoparasite Pythium oligandrum. Soil Biol. Biochem. 18:91-95.

15. Frens, G. 1973. Controlled nucleation for the regulation of the particle size in monodisperse gold solution. Nat. Phys. Sci. 241:20-22.

16. Goldman, G. H., Hayes, C., and Harman, G. E. 1994. Molecular and cellular biology of biocontrol by Trichoderma spp. Trends Biotechnol. 12:478-482.

17. Howell, C. R., Stipanovic, R. D., and Lumsden, R. D. 1993. Antibiotic production by strains of Gliocladium virens and its relation to the biocontrol of cotton seedling diseases. Biocontrol Sci. Technol. 3:435-441.

18. Inbar, J., and Chet, I. 1992. Biomimics of fungal cell-cell recognition by use of lectin-coated nylon fibers. J. Bacteriol. 174:1055-1059.

19. Jones, E. E., and Deacon, J. W. 1995. Comparative physiology and behavior of the mycoparasites Pythium acanthophoron, P. oligandrum and P. mycoparasiticum. Biocontrol Sci. Technol. 5:27-39.

20. Klekan, A. L., Hippe, S., and Lumsden, R. D. 1990. Reduced growth of Erysiphe graminis f. sp. hordei induced by Tilletiopsis pallescens. Phytopathology 80:325-331.

21. Laing, S. A. K., and Deacon, J. W. 1990. Video microscopical comparison of mycoparasitism by Pythium oligandrum, Pythium nunn, and an unnamed Pythium species. Mycol. Res. 95:469-479.

22. Lewis, K., Whipps, J. M., and Cooke, R. C. 1989. Mechanisms of biological disease control with special reference to the case study of $P y$ thium oligandrum as an antagonist. Pages 191-217 in: Biotechnology of Fungi for Improving Plant Growth. J. M. Whipps and R. D. Lumdsen, eds. Cambridge University Press, Cambridge.

23. Lutchmeah, R. S., and Cooke, R. C., 1984. Aspects of antagonism by the mycoparasite Pythium oligandrum. Trans. Br. Mycol. Soc. 83:696-700.

24. Martin, F. N., and Hancock, J. G. 1987. The use of Pythium oligandrum for biological control of preemergence damping-off caused by $P$. ultimum. Phytopathology 77:1013-1020.

25. Nes, W. D., and Heftmann, E. 1981. A comparison of triterpenoids with steroids as membrane components. J. Natl. Prod. (Lloydia) 44: 377-400.

26. Robertson, R. W., and Fuller, M. S. 1990. Effects of the demethylase inhibitor, cyproconazole, on hyphal tip cells of Sclerotium rolfsii. II. An electron microscope study. Exp. Mycol. 14:124-135.

27. Rousseau, A., Benhamou, N., Chet, I., and Piché, Y. 1996. Mycoparasitism of the extramatrical phase of Glomus intraradices by Trichoderma harzianum. Phytopathology 86:434-443.

28. Sanderman, Jr., H. 1978. Regulation of membrane enzymes by lipids. Biochim. Biophys. Acta 515:209-237.

29. Whipps, J. M. 1987. Effect of media on growth and interactions between a range of soil-borne glasshouse pathogens and antagonistic fungi. New Phytol. 107:127-142. 